\title{
CXCL9 and CXCL10 display an age- dependent profile in Chagas patients: a cohort study of aging in Bambui, Brazil
}

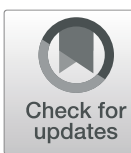

Fernanda Fortes de Araújo ${ }^{1 \dagger}$, Karen Cecília Lima Torres ${ }^{1,2+}$, Sérgio Viana Peixoto ${ }^{3}$, Antonio Luiz Pinho Ribeiro ${ }^{4}$, Juliana Vaz Melo Mambrini ${ }^{3}$, Vitor Bortolo Rezende ${ }^{1}$, Maria Luiza Lima Silva ${ }^{3}$, Antônio Ignácio Loyola Filho ${ }^{3}$, Andréa Teixeira-Carvalho ${ }^{1}$, Maria Fernanda Lima-Costa ${ }^{3}$ and Olindo Assis Martins-Filho ${ }^{1 *}$

\begin{abstract}
Background: Chagas disease is endemic in Latin America and still represents an important public health problem in the region. Chronic cardiomyopathy is the most significant chronic form due to its association with morbidity and mortality. The last decade has seen increasing evidence that inflammatory cytokines and chemokines are responsible for the generation of inflammatory infiltrate and tissue damage, with chronic chagasic cardiomyopathy patients presenting a pro-inflammatory immune response. Although studies have evaluated the role of chemokines in experimental T. cruzi infection, few have addressed their systemic profile, especially for human infection and in aging populations. The present work aimed to use the data from a large population based study of older adults, conducted in an endemic area for Chagas disease, to examine the association between serum levels of cytokines and chemokines, T. cruzi infection and electrocardiogram (ECG) abnormality.
\end{abstract}

Methods: The present work evaluated serum levels of CCL2, CXCL9, CXCL10, CCL5, CXCL8, IL-1ß, IL-6, TNF, IL-12 and IL-10 by Flow Cytometric Bead Array assay (CBA) and the results expressed in pg/ml. The baseline survey started in January 1st 1997, with 1284 participants of an aged population-based cohort. Participants signed an informed consent at baseline and at each subsequent visit and authorized death certificate and medical records verification.

Results: Our results demonstrated that Chagas disease patients had higher serum levels of CXCL9, CXCL10 and IL-1 $\beta$ and lower serum levels of CCL5 than non-infected subjects. Moreover, our data demonstrated that CXCL9 and CXCL10 increased in an age-dependent profile in Chagas disease patients.

Conclusion: Together, this study provided evidences that serum biomarkers increase along the age continuum and may have potential implications for establishing clinical management protocols and therapeutic intervention in Chagas disease patients.

Keywords: Chagas disease, Immune biomarkers, Chemokines, Cytokines, Cohort

* Correspondence: oamfilho@gmail.com

${ }^{\dagger}$ Fernanda Fortes de Araújo and Karen Cecília Lima Torres contributed equally to this work.

${ }^{1}$ Integrated Research Group in Biomarkers, Rene Rachou Institute, Oswaldo Cruz Foundation, Avenida Augusto de Lima, 1715 - Barro Preto -, Belo Horizonte, Minas Gerais 30190-002, Brazil

Full list of author information is available at the end of the article

\section{Background}

Chagas disease $(\mathrm{CD})$ or American trypanosomiasis is an infection caused by Trypanosoma cruzi, a protozoan that is endemic in Latin America [1]. The disease has spread throughout the world, but especially in the United States, Europe, Asia and Oceania due to international immigration [2]. There are estimates that about 8 
million people are currently infected with $T$. cruzi, mainly in Latin America, with risk of developing chronic forms of the disease [3].

There are important knowledge gaps about the natural history of $\mathrm{CD}$ and its clinical course is highly variable. Most infected individuals develop the chronic phase of the disease and many remain asymptomatic throughout their lifetime, in the indeterminate form of the disease, while 20 to $40 \%$ develop cardiac or digestive forms [1,3]. Cardiac cardiomyopathy is the most important chronic form of Chagas disease, because of its association with morbidity and mortality and the consequent medical and social impact [4]. Infected patients with the chronic indeterminate form evolve to Chagas cardiomyopathy at a rate of $2 \%$ annually [5], but which patients and why they develop heart diseases (and others do not) is largely unknown.

The mechanisms involved on the development of severe forms of Chagas disease are not well defined. However, previous studies have demonstrated the importance of immune response in disease progression and that the balance between inflammatory and anti-inflammatory cytokines produced by circulating cells in patients with indeterminate clinical form leans towards an antiinflammatory profile, contributing to the control of the disease in these patients. On the other hand, cardiac patients developed a Th1-specific immune response that is associated with morbidity [6-10].

The last decade has seen increasing evidence that inflammatory cytokines and chemokines are responsible for the generation of inflammatory infiltrate and tissue damage [11]. Previous studies have demonstrated that mononuclear cells infiltrating CCC heart tissue express IFN $-\gamma$, TNF and IL-6, with lower levels of IL-2, IL-4 and IL-10 [12-14]. Moreover, specific chemokines are produced in tissue in response to T. cruzi infection and are crucial in defining leukocyte subtypes that compose the inflammatory infiltrate in the heart of infected animals [15-17]. Furthermore, Cunha-Neto et al., [18] detected mononuclear cells that express CXCR3, CCR5, CXCL9 and CCL5 in the myocardium of CCC patients using confocal immunofluorescence assays. These authors suggested that IFN- $\gamma$-dependent chemokines, such as CCL5, CXCL9 and CXCL10, may increase the chemotactic signal and cause migration of more $\mathrm{T}$ lymphocytes to the myocardium. Although studies have evaluated the role of chemokines in experimental T. cruzi infection, few studies have addressed their profile, especially in human infection.

We used data from a large population based study of older adults conducted in and endemic area for Chagas disease to examine the association between serum levels of cytokines and chemokines, T. cruzi infection and electrocardiogram (ECG) abnormality, taking into account an array of potential confounding variables.

\section{Methods}

\section{Study design and population}

The cohort study of aging is ongoing in Bambuí, a city of approximately 15000 inhabitants in the state of Minas Gerais in Southeast Brazil, which is one of the oldest known endemic areas for Chagas disease [19-21]. Detailed information on this cohort can be found elsewhere [22]. Briefly, a cohort baseline survey was conducted in 1997 and the study population was identified by a complete census in the city. Participants signed an informed consent at baseline and at each subsequent visit and authorized death certificate and medical records verification. All residents aged 60 or older (1742) were invited to join the study; 1496 (85.9\%) authorized blood sample tests.

The Bambui cohort included in this study presented an overall seroprevalence of $37.5 \%$ for T. cruzi infection, including $35.6 \%$ for patients aged 60 to 69 years old, and $40.5 \%$ for both patients aged 70 to 79 and $80+$ years old. According to previous studies carried out in the area of Bambui city, TcII is the predominant genotype being found in approximately $77.6 \%$ of $T$. cruzi infected patients [23].

This study was approved by the Ethics Research Committee at Fundação Oswaldo Cruz (CAAE 01082212.7.0000.5091). All participants signed an informed consent form for all procedures.

\section{Chagas disease serology}

Serology for $T$. cruzi infection was assessed by three different assays performed concurrently: a hemagglutination assay (Biolab Merieux SA, Rio de Janeiro, Brazil) and two enzyme- linked immunosorbent assays (Abbott Laboratories, Inc., North Chicago, Illinois; and Wiener Laboratories, Rosario, Argentina). Infection with T. cruzi was defined by seropositivity in all three of the assays; seventeen persons had discordant results among the assays and were excluded from the analysis.

\section{Electrocardiogram (ECG)}

At the baseline examination, a digitally recorded 12-lead ECG (Hewlett Packard MI700A) reading was obtained at rest. The ECGs were analyzed at the ECG Reading Center (EPICARE, Wake Forest University) and classified using the Minnesota Code (MC) classification system for electrocardiographic findings using " $x$ " to assign subclassification criterion [24, 25]. Major ECG abnormalities were defined by the presence of at least one of the following: old (MC 1.1.x or 1.2.x) or possible myocardial infarction (1.3.x and 4.1.x, 4.2, 5.1, or 5.2), complete intraventricular blocks (MC 7.1, 7.2, 7.4, or 7.8), frequent supraventricular or ventricular premature beats (MC 8.1.x, except 8.1.4), major isolated ST segment or T-wave abnormalities (MC 4.1.x, 4.2, 5.1 or 5.2), atrial fibrillation or flutter or supraventricular tachycardia (MC 8.3.x. or 8.4.2), other major arrhythmias (MC 8.2.x, except 8.2.1), 
major atrioventricular conduction abnormalities or pacemaker use (MC 6.1, 6.2.x, 6.4, 6.8, 8.6.1 or 8.6.2), major QTi prolongation $(>115 \%)$ and left ventricular hypertrophy (LVH) (MC 3.1 together with [4.1.x, 4.2, 5.1, or 5.2]). Further details can be seen elsewhere [26].

\section{Biomarkers (cytokines and chemokines)}

Blood samples for the measurement of cytokines and chemokines were collected at the baseline survey in early morning. The Cytometric Bead Array assay (CBA immunoassay kit; Becton, Dickinson and Company BD Life Sciences - Biosciences, San Jose, CA, USA) was used for quantitative determination of serum cytokines (Human Inflammatory kit) and chemokines (Human Chemokines kit) according to manufacturer (Becton, Dickinson and Company BD Life Sciences - Biosciences, San Jose, CA, USA). The Inflammatory CBA kit comprises microbeads coupled to monoclonal antibodies (MoAb) against the following cytokines IL-6, IL-12, TNF, IL-10, and IL$1 \beta$, and the chemokine CBA kit detects CXCL8, CCL2, CXCL9, CCL5 and CXCL10. A second fluorescently labelled phycoerythrin (PE)-anti-cytokine antibody was used and the concentration of the individual cytokines was indicated by fluorescence intensity. Data was acquired using a FACSVerse flow cytometer (Becton Dickinson, USA). Sample analysis was performed with BD FCAP Array 3.0 software (Becton, Dickinson and Company BD Life Sciences - Biosciences, San Jose, CA, USA). The coefficients of variation for intra and interassays were $5-10 \%$ and $7-12 \%$, respectively.

\section{Potential confounding variables}

Potential confounding variables in our analysis included socio-demographic characteristics (age, gender, schooling and family income), lifestyle (current smoking, physical activity and alcohol consumption), chronic diseases and medication use (digoxin and anti-inflammatory medication). Monthly family income per capita was divided into tertiles (< USD 90.00 was the lowest tertile). Current smokers were those who had smoked at least 100 cigarettes during their lifetimes and who were still smokers. Physical activity was calculated based on the level of oxygen consumed for 25 physical activities in the previous 3 months, as described elsewhere [27]. Sedentary individuals were considered to be those whose energy expenditure was less than 450 metabolic equivalent tasks, which corresponds to at least $150 \mathrm{~min}$ per week of moderately to vigorously physical activity [27]. Alcohol consumption was defined by consumption of 14 doses or more per week in the previous 12 months. Chronic diseases considered in our analysis were: hypertension (systolic blood pressure $\geq 140 \mathrm{mmHg}$ and/or diastolic blood pressure $\geq 90 \mathrm{mmHg}$ and/or treatment); diabetes (fasting blood glucose $\geq 7.0 \mathrm{mmol} / \mathrm{L}$ and/or treatment); arthritis and myocardial infarction as defined by a previous medical diagnosis for the condition; stroke, using a standard protocol [28]; total cholesterol $(\mathrm{mmol} / \mathrm{L})$, triglycerides $(\mathrm{mmol} / \mathrm{L})$, body mass index $\left(\mathrm{kg} / \mathrm{m}^{2}\right)$ and creatinine level ( $\mu \mathrm{mol} / \mathrm{L}$ ) (as continuous variables); depressive symptoms, which were calculated using the 12 -item version of the General Health Questionnaire; a score $\geq 5$ was considered the cut-off for defining exposure status, as recommended for the study population [29].

Fasting total cholesterol, triglycerides, glucose and creatinine were determined by using standard enzymatic methods (Merck, Darmstadt, Germany). Body mass index (BMI) was defined by weight divided by height squared $\left(\mathrm{kg} / \mathrm{m}^{2}\right)$. Current medication use was ascertained during the home interview by reviewing prescriptions and/or medication packaging. Blood Pressure (BP) was measured 30 or more minutes after the last caffeine intake or cigarette smoked. Three measures were taken after $5 \mathrm{~min}$ of initial rest and subsequently at 2-min intervals.

\section{Statistical analysis}

The outcome variables were ten biomarkers (cytokines and chemokines), as previously described. Based on their distribution, IL-6, CXCL10, CCL2, CXCL9, CCL5 and CXCL8 were dichotomized as above or below the median (coded 1 and 0 , respectively). Given their lower values, IL-12, TNF, IL-10 and IL-1 $\beta$ were dichotomized as the lowest detectable value vs. non-detectable (coded as 1 and 0 , respectively). The exposure variables were $T$. cruzi infection and ECG abnormality, which were categorized as follows: seronegative non-infected $(\mathrm{NI}=$ reference category), infected without major ECG abnormalities (CH (N) ECG) and infected with major ECG abnormality (CH (Ab) ECG).

Pearson's chi square test was used in bivariate analyses to assess the statistical significance of differences across the three groups described above. Multivariate analyses were conducted for the biomarkers that showed significant association $(P<0.05)$ in the previous analysis, considering adjustment for all potential confounders included in the present study. For this analysis, the biomarkers were dichotomized or divided in tertiles, according to their distribution. The adjusted odds ratio and $95 \%$ confidence intervals were estimated for binary logistic or multinomial logistic regression. The predicted probability was then estimated and plotted for each biomarker, considering the possible interaction between age and T. cruzi infection/ECG abnormality.

Since there was no evidence of interaction with sex $(P$ value for interaction $>0.05$ for all), the analyses were carried out for both men and women with sex included as a covariate. All analyses used Stata version 13 (StataCorp LLP, College Station, TX). 


\section{Results}

Baseline characteristics of the study participants

Of the 1606 baseline cohort participants, 1284 had complete information for all study variables and were included in the current analysis. The baseline characteristics of the study participants are shown in Table 1. Among study participants, the mean age was 68.8 years with women predominating (61.9\%). Statistically significant differences $(P<0.05)$ across the study groups (seronegative-NI, seropositive with and without electrocardiogram ECG abnormalities) were found for age, gender, educational level, family income, depressive symptoms, body mass index, serum creatinine level and digoxin use (Table 1).

\section{Bivariate association between $T$. cruzi infection and serum biomarker levels}

Bivariate analysis between ten biomarkers and the study groups above mentioned is demonstrated at Table 2 . Statistically significant associations were found for serum concentration $(\mathrm{pg} / \mathrm{ml})$ of CXCL9, CXCL10, and CCL5 above or below the median levels and also for serum detectable levels of IL- $1 \beta$.

\section{Multivariate analysis of inflammatory markers and $T$. cruzi infection}

The statistically significant results of the multivariate analysis of the association between Trypanosoma cruzi infection and biomarkers are presented at Table 3. After adjustments for potential confounders, positive and independent positive associations were found from the biomarkers evaluated showing that the groups $\mathrm{CH}(\mathrm{N})$ ECG and $\mathrm{CH}(\mathrm{Ab})$ ECG presented an odds ratio $(O R)$ of 4.14 and 3.02 for CXCL9; 2.26 and 2.95 for CXCL10; 2.65 and 1.57 for CCL5; 5.02 and 3.94 for the cytokine IL-1 $\beta$, respectively, suggesting significant differences in the levels of cytokines/chemokines among the groups studied.

\section{Predicted probability for variation in serum biomarker levels along the age continuum}

The results of the predicted probability of changes in serum chemokines/cytokines levels (CXCL9, CXCL10, CCL5 and IL-1- $\beta$ ) along the age continuum revealed that CXCL9 and CXCL10 levels from all groups increased along the age continuum, suggesting a strong association between the production of these biomarkers and elderly

Table 1 Baseline characteristics of study participants and by Trypanosoma cruzi infection serological status

\begin{tabular}{|c|c|c|c|c|c|}
\hline Characteristics & $\begin{array}{l}\text { TOTAL } \\
(n=1284)\end{array}$ & $\begin{array}{l}\mathrm{NI} \\
(n=802)\end{array}$ & $\begin{array}{l}\mathrm{CH}(\mathrm{N}) \mathrm{ECG} \\
(n=210)\end{array}$ & $\begin{array}{l}\mathrm{CH}(\mathrm{Ab}) \mathrm{ECG} \\
(n=272)\end{array}$ & $P$ value \\
\hline Age in years, mean (SD) & $68.8(6.9)$ & $68.5(7.0)$ & $68.0(6.6)$ & $70.4(6.9)$ & $<0.001$ \\
\hline Female, \% & 61.9 & 57.4 & 70.5 & 68.8 & $<0.001$ \\
\hline Schooling < 4 years, \% & 63.7 & 51.4 & 82.4 & 85.7 & $<0.001$ \\
\hline Family income ${ }^{a}, \%$ & 27.4 & 24.8 & 31.9 & 31.6 & 0.026 \\
\hline Current smoking ${ }^{\mathrm{b}}, \%$ & 17.0 & 17.5 & 15.7 & 16.5 & 0.817 \\
\hline Alcohol consumption` ${ }^{c} \%$ & 2.2 & 2.0 & 1.9 & 2.9 & 0.624 \\
\hline Sedentary lifestyle ${ }^{d}, \%$ & 26.7 & 25.4 & 29.1 & 28.7 & 0.409 \\
\hline Arthritis ${ }^{\mathrm{e}}, \%$ & 31.9 & 32.2 & 31.4 & 31.3 & 0.951 \\
\hline Diabetes $^{f}, \%$ & 14.8 & 17.3 & 9.1 & 11.8 & 0.003 \\
\hline Myocardial infarction, \% & 4.7 & 4.6 & 3.3 & 5.9 & 0.418 \\
\hline Stroke,$\%$ & 3.4 & 2.6 & 3.3 & 5.5 & 0.072 \\
\hline Hypertension ${ }^{g}, \%$ & 61.5 & 61.6 & 57.1 & 64.3 & 0.271 \\
\hline Depressive symptoms ${ }^{\mathrm{h}}, \%$ & 37.6 & 33.2 & 41.4 & 47.8 & $<0.001$ \\
\hline Total Cholesterol (mmol/L), mean (SD) & $6.0(1.3)$ & $6.0(1.2)$ & $6.1(1.3)$ & $6.0(1.3)$ & 0.992 \\
\hline Triglycerides (mmol/L), mean (SD) & $1.7(1.1)$ & $1.8(1.2)$ & $1.7(1.1)$ & $1.6(1.0)$ & 0.181 \\
\hline Body mass index, mean (SD) & $25.2(5.0)$ & $25.6(4.9)$ & $25.0(5.0)$ & $24.0(5.2)$ & $<0.001$ \\
\hline Creatinine $(\mu \mathrm{mol} / \mathrm{L})$, mean $(S D)$ & $80.0(30.0)$ & $80.0(30.0)$ & $70.0(20.0)$ & $80.0(20.0)$ & 0.040 \\
\hline Digoxin use, \% & 14.4 & 10.4 & 17.1 & 24.3 & $<0.001$ \\
\hline Anti-inflammatory medication, \% & 16.2 & 15.8 & 18.6 & 15.4 & 0.587 \\
\hline
\end{tabular}

CH: Chagas disease patients; NI: Non-infected subjects; N: Normal; Ab: Abnormal; ECG: Electrocardiogram; SD: standard deviation.

${ }^{a}$ Monthly family income per capita (lowest tertile); ${ }^{b}$ Current smoking (who had smoked at least 100 cigarettes during their lifetimes and who were still smokers);

${ }^{\mathrm{c}}$ Alcohol consumption in previous 12 months ( $>14$ doses per week); ${ }^{\mathrm{d} S e d e n t a r y}$ Lifestyle $\left(<150\right.$ min of physical activity per week); ${ }^{\mathrm{e}}$ Arthritis and Stroke (medical diagnosis); ${ }^{f}$ Diabetes (fasting blood glucose $\geq 7.0 \mathrm{mmol} / \mathrm{L}$ and/or treatment); ${ }^{9}$ Hypertension (systolic blood pressure $\geq 140 \mathrm{mmHg}$ and/or diastolic blood pressure $\geq 90 \mathrm{mmHg}$ and/or treatment); ${ }^{\mathrm{h}}$ Depressive symptoms (General Health Questionnaire score $\geq 5$ ); $P$ value from ANOVA for continuous variables and chi square test for categorical variables 
Table 2 Bivariate association between Trypanosoma cruzi infection and serum chemokines/cytokines levels above the median or detectable values

\begin{tabular}{|c|c|c|c|c|}
\hline \multirow[t]{2}{*}{ Biomarkers* } & \multicolumn{3}{|c|}{ Percentage above the global median } & \multirow[t]{2}{*}{$P$ value } \\
\hline & $\overline{\mathrm{Nl}}$ & $\mathrm{CH}(\mathrm{N}) \mathrm{ECG}$ & $\mathrm{CH}(\mathrm{Ab}) \mathrm{ECG}$ & \\
\hline \multicolumn{5}{|l|}{ Chemokines (cut-offs) } \\
\hline CCL2 ( $\geq 50.24$ pg/ml) & 33.3 & 31.4 & 33.8 & 0.843 \\
\hline CXCL9 ( $\geq 3485.80$ pg/ml) & 21.9 & 47.6 & 54.4 & $<0.001$ \\
\hline CXCL10 ( $\geq 4014.77 \mathrm{pg} / \mathrm{ml})$ & 23.8 & 46.2 & 50.0 & $<0.001$ \\
\hline $\operatorname{CCL} 5(<630.37 \mathrm{pg} / \mathrm{ml})$ & 36.4 & 22.9 & 31.3 & $<0.001$ \\
\hline CXCL8 ( $\geq 4.41 \mathrm{pg} / \mathrm{ml})$ & 33.8 & 30.0 & 32.0 & 0.553 \\
\hline \multicolumn{5}{|l|}{ Cytokines (cut-offs) } \\
\hline $\mathrm{IL}-1 \beta(\geq 0.01 \mathrm{pg} / \mathrm{ml})$ & 12.2 & 41.9 & 37.1 & $<0.001$ \\
\hline IL-6 ( $\geq 1.65 \mathrm{pg} / \mathrm{ml})$ & 32.4 & 29.5 & 37.5 & 0.153 \\
\hline $\operatorname{TNF}(\geq 0.01 \mathrm{pg} / \mathrm{ml})$ & 16.8 & 17.6 & 18.0 & 0.892 \\
\hline $\mathrm{IL}-12(\geq 0.01 \mathrm{pg} / \mathrm{ml})$ & 7.6 & 6.7 & 8.8 & 0.668 \\
\hline $\mathrm{IL}-10(\geq 0.07 \mathrm{pg} / \mathrm{ml})$ & 32.8 & 33.3 & 39.3 & 0.138 \\
\hline
\end{tabular}

CH Chagas disease patients, NI Non-infected subjects, $N$ Normal, Ab Abnormal, ECG Electrocardiogram, TNF Tumor necrosis factor, IL-6 Interleukin 6, IL-1 $\beta$ Interleukin 1 beta, IL-10 Interleukin 10, IL-12 Interleukin 12, CXCL9 C-X-C motif chemokine ligand-9, CCL5 C-C motif chemokine ligand 5, CXCL10 C-X-C motif chemokine ligand-10, CXCL8 C-X-C motif ligand 8, CCL2 C-C motif chemokine ligand 2

${ }^{*}$ Cut-offs points above the median except for IL-1 $\beta$, TNF, IL-12 and IL-10 (detectable values). $P$ value: from chi-square test. Altered levels according to cut-offs. $P$ value of chi-square test

patients. No association was observed between levels of IL-1 $\beta$ and CCL5 and age (Fig. 1). Moreover, Fig. 1b clearly shows that the groups $\mathrm{CH}(\mathrm{N})$ ECG and $\mathrm{CH}(\mathrm{Ab})$ ECG had higher numbers of individuals with high levels of CXCL9 and CXCL10 and that this is associated with age, suggesting changes in serum levels of these biomarkers during aging.
Regarding potential confounding variables, it is important to mention that none of the cohort participants had a history of anti- $T$. cruzi etiological treatment on entry into the cohort, and none received treatment during the period in which patients were followed [21]. However, the lack of information about treatment for other infectious diseases or about conditions of re-

Table 3 Multivariate analysis of the association between inflammatory markers and Trypanosoma cruzi infection

\begin{tabular}{|c|c|c|c|}
\hline \multirow[t]{3}{*}{ Serum levels in tertiles } & \multicolumn{3}{|c|}{$\begin{array}{l}\text { Infection status - odds ratio } \\
(95 \% \text { confidence interval) }\end{array}$} \\
\hline & \multirow[t]{2}{*}{ Negative } & \multicolumn{2}{|l|}{ Positive } \\
\hline & & $\mathrm{CH}(\mathrm{N}) \mathrm{ECG}$ & $\mathrm{CH}(\mathrm{Ab}) \mathrm{ECG}$ \\
\hline \multicolumn{4}{|l|}{ CXCL9 (pg/ml) } \\
\hline Intermediate (1569.1-3483.0) & 1.00 & $1.25(0.79-2.00)$ & $0.68(0.45-1.04)$ \\
\hline Highest (> 3483.0) & 1.00 & $4.14(2.65-6.48)$ & $3.02(2.05-4.45)$ \\
\hline \multicolumn{4}{|l|}{ CXCL10 (pg/ml) } \\
\hline Intermediate (2352.8-4018.0) & 1.00 & $0.90(0.59-1.37)$ & $1.17(0.78-1.75)$ \\
\hline Highest (> 4018.0) & 1.00 & $2.26(1.52-3.37)$ & $2.95(2.00-4.34)$ \\
\hline \multicolumn{4}{|l|}{ CCL5 (pg/ml) } \\
\hline Intermediate (644.7-1263.6) & 1.00 & $1.93(1.26-2.95)$ & $1.40(0.96-2.03)$ \\
\hline Lowest (<644.7) & 1.00 & $2.65(1.75-4.02)$ & $1.57(1.08-2.28)$ \\
\hline \multicolumn{4}{|l|}{ IL $1-\beta$ (pg/ml) } \\
\hline Detectable (> 0.01) & 1.00 & $5.02(3.46-7.27)$ & $3.94(2.76-5.63)$ \\
\hline
\end{tabular}

CH Chagas disease patients, $N$ Normal, Ab Abnormal, ECG Electrocardiogram, CXCL9 C-X-C motif chemokine ligand-9, CCL5 C-C motif chemokine ligand 5, CXCL10 $\mathrm{C}-\mathrm{X}-\mathrm{C}$ motif chemokine ligand- 10

*Estimated by multinomial ${ }^{1}$ or binomial logistic ${ }^{2}$ regression and adjusted for all variables listed in Table 1. First tertile as a reference category for CXCL10 and CXCL9; third tertile is a reference category for CCL5 

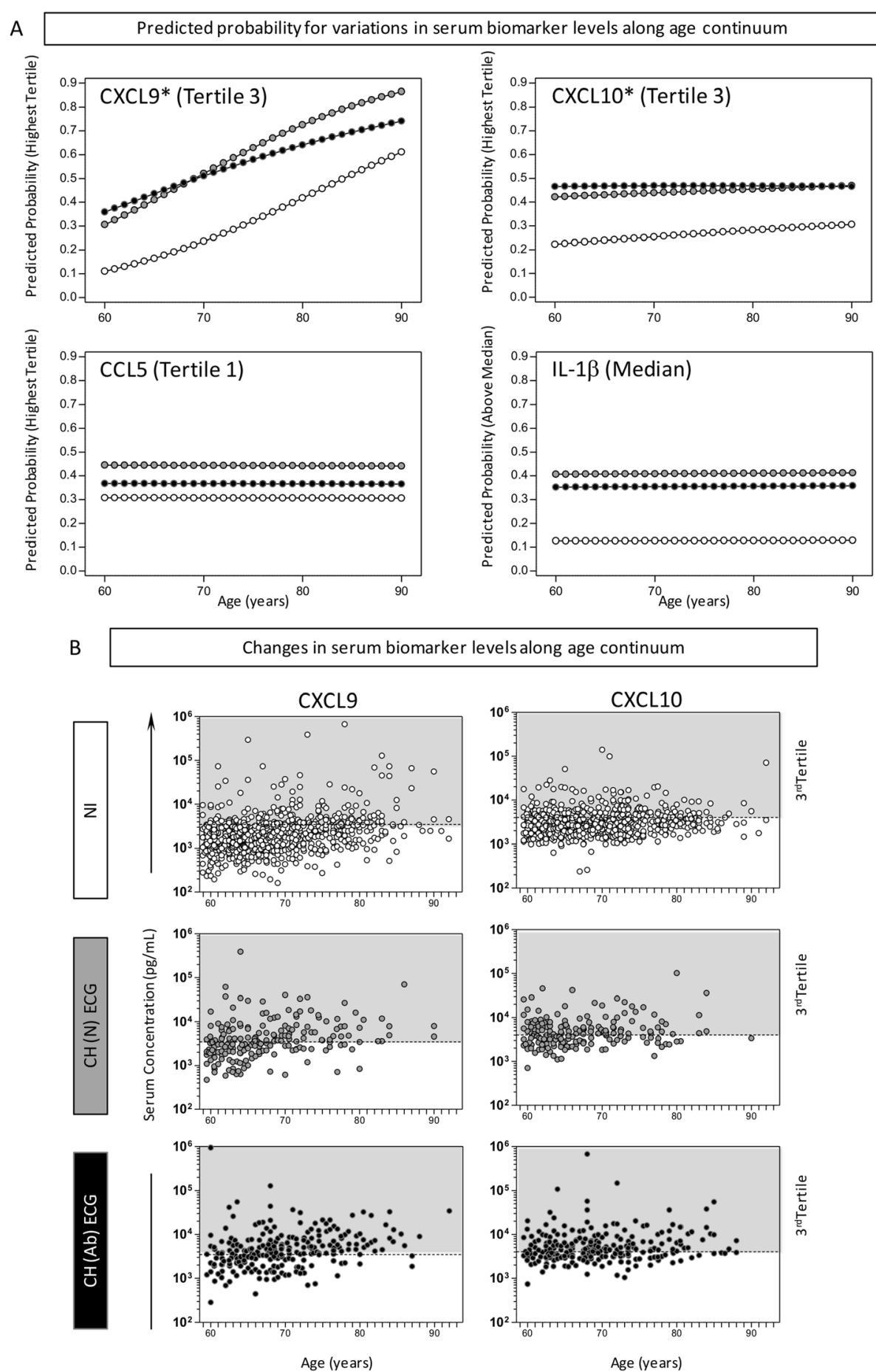

Fig. 1 Predicted probability for variations in serum biomarker levels along age continuum. a Predicted probability of high producers of serum biomarkers (CXCL9, CXCL10, CCL5 and IL-1 $\beta$ ) along ageing continuum for Chagas disease subgroups CH(N) ECG (O); CH (Ab) ECG (•) and noninfected controls $\mathrm{NI}(\mathbf{O})$. b Scattering distribution of changes in CXCL9 and CXCL10 levels along age continuum. The gray background underscored the 3rd Tertile to highlight the higher proportion of $\mathrm{CH}$ (Ab) ECG subjects above the threshold. The modeled system employed is described in methods section. IL-1ß: Interleukin 1 beta CXCL9: C-X-C motif chemokine ligand-9; CCL5: C-C motif chemokine ligand 5; CXCL10: CX-C motif chemokine ligand-10; ECG: Electrocardiogram; NI: Seronegative non-infected; $\mathrm{CH}$ (N) ECG: infected without major ECG abnormalities; $\mathrm{CH}$ (Ab) ECG: infected with major ECG abnormality 
infection could be residual confounders for the associations between $T$. cruzi infection and inflammatory markers.

\section{Discussion}

This large population-based cohort study provided unique information about the characteristics of the study participants and T. cruzi infection. Our data showed significant and positive associations between T. cruzi infection and female gender, body mass index, digoxin use and depression. Moreover, our data showed a strong association between low schooling level (an indicator of socioeconomic status) and T. cruzi infection.

Previous studies have shown that inflammatory cytokines and chemokines play a central role in $T$. cruzi infection [6-8]. Inflammation is a key mechanism in the initiation, progression and clinical manifestations of Chagas heart disease in which the presence of $T$. cruzi or its antigens triggers an uncontrolled humoral and / or cellular immune response. Our data showed that infected Chagas patients presented significantly increased levels of the cytokine IL-1 $\beta$ and the chemokines CXCL10 and CXCL9, and decreased levels of CCL5, when compared to noninfected individuals (Tables 2 and 3).

Chagas disease is a lifelong infection in humans that can be manifested many years after initial infection. Moreover, inflammation disproportional to parasite load characterizes chronic myocardial lesions in chagasic individuals. It has been reported that plasma levels of IL$1 \beta$ were increased in the early phase of acute myocardial infarction and that the increase was observed prior to the peak plasma levels of brain natriuretic peptide/BNP $[30,31]$. Also, the expression of IL-1 $\beta$ mRNA has been observed in the infarct region of the heart [32]. Thus, these authors hypothesized that IL-1 $\beta$ might induce BNP secretion and cardiac hypertrophy in acute myocardial infarction or heart failure [33]. Additionally, Sousa et al., [34] evaluated plasma cytokine levels in well defined clinical polar groups of chronic Chagas patients and observed that inflammatory cytokine expression, including IL-1 $\beta$, was highest in the cardiac (CARD) group.

Further studies about hypertrophic response in $T$. cruzi-infected cardiac myocytes identified the proinflammatory cytokine IL- $1 \beta$ as an important mediator. These authors demonstrated, by the addition of a specific cytokine trap to infected cardiac myocyte cultures, that blocking the activity of IL-1 $\beta$ leads to a significant reduction of the overall hypertrophic response. Indeed, IL$1 \beta$, which is rapidly induced in response to $T$. cruzi, promotes cardiomyocyte hypertrophy early in the infective process and may contribute to the maintenance of cardiomyocyte function during establishment of T. cruzi infection in the heart [35, 36]. Medeiros et al., [37] demonstrated that patients with the cardiac clinical form had increased IL-1 $\beta$ associated with metalloproteinase (MMP-9) and alternative caspase-1-independent pathway. These findings, together with our data that showed high levels of IL-1 $\beta$ in Chagas patients, suggest that this cytokine has an important role in disease progression.

Few studies have evaluated the relevance of chemokines for T. cruzi infection in humans but studies on experimental infection showed that during chronic infection of C57BL/6 mice with the Colombian strain of T. cruzi, as in the acute experiments, there was a clear correlation between the migration of leukocyte subsets and the expression of particular chemokines [38, 39]. Importantly, CXCL10, CXCL9 and CCL5 were produced throughout the course of infection (until day 120), even when tissue parasitism was low [38]. Also, CXCL10 and CCL5 were found to be among the dominant cytokines expressed in situ during acute experimental infection and chronic phase of $T$. cruzi-elicited myocarditis contributing to intense recruitment of activated T cells [40].

Our data corroborate these findings, except for the low levels of CCL5 presented by $\mathrm{CH}(\mathrm{N})$ ECG patients. Marino et al. [15] demonstrated that most of the inflammatory cells invading the heart tissue during the early phase of $T$. cruzi infection of $\mathrm{C} 3 \mathrm{H} / \mathrm{HeJ}$ mice were $\mathrm{CD}^{+} \mathrm{T}$ cells and that they expressed CCR5, a CCL5 receptor. In humans, previous studies found increased percentages of effector $\mathrm{CD} 4^{+} \mathrm{T}$ cells and central memory $\mathrm{CD} 4^{+}$and $\mathrm{CD} 8^{+} \mathrm{T}$ cells expressing CCR5 in patients with structural cardiopathy, but normal global ventricular function and no symptoms of chronic heart failure [41]. However, a recent work from Luz et al. [42] with chronic human patients did not show any difference in the levels of CCL5 in plasma samples of Chagas patients and controls. In fact, Chagas patients presented lower levels than controls $(8829.0 \mathrm{pg} / \mu \mathrm{l}$ vs 9259.0 $\mathrm{pg} / \mu \mathrm{l} ; P=0.052$ ). This finding is corroborated by our results indicating that CCL5 is more important in situ instead of systemic response.

Interestingly, Crema et al. [43] also showed that CXCL9 levels were significantly higher in chagasic patients with megaesophagus compared to individuals without the disease. In addition, studies have shown significantly higher levels of CXCL10 in patients with chronic Chagas disease when compared to controls, suggesting that CXCL10 may contribute to inflammation and consequent tissue injury in the cardiac form of $\mathrm{CD}[42,44]$. Additionally, our results showed that levels of CXCL9 and CXCL10 for Chagas patients increased along age continuum, suggesting an association between these chemokines and elderly patients. Furthermore, CXCL10 has been considered a novel biomarker for severity of parasitic diseases [45].

Also, Cunha-Neto et al. [18] showed that IFN- $\gamma$ dependent chemokines, such as CCL5, CXCL9 and CXCL10, may increase the chemotactic signal and cause migration of more $\mathrm{CCR}^{+}{ }^{+} \mathrm{CXCR}^{+}{ }^{+} \mathrm{T}$ lymphocytes to 
the myocardium. Recent studies by this group showed that genetic variation in chemokines genes could be associated with CCC development. These authors demonstrated that polymorphisms in CXCL9, CXCL10 and CCR5 were associated with differential risk of progression to the more severe form of CCC, suggesting that such chemokines may be master regulators of myocardial inflammatory cell migration, perhaps affecting clinical progression to severe CCC [46].

This study may present limitations inherent of observational investigation and should be further validated by long-term longitudinal follow up. Since Bambui city has been considered a geographical area endemic for Chagas disease for many decades, it is possible that most patients acquired the infection at childhood and, therefore, these changes in serum biomarker profiles may be the result of a multifactorial process that includes both the ageing process and the time elapsed since $T$. cruzi primo-infection.

\section{Conclusions}

Our results provide new evidence supporting the importance of the cytokine IL-1 $\beta$ and the chemokines CXCL9, CXCL10 and CCL5 in T. cruzi chronic infection in humans. Levels of CXCL9 and CXCL10 for Chagas patients increase along the age continuum, suggesting a strong association between the production of these chemokines and elderly patients. Moreover, the association of two or more biomarkers, especially CCL5 and IL1- $\beta$, may indicate the progression of clinical symptoms in Chagas patients. Thus, the functional role of particular chemokines in host resistance to infection and in the pathogenesis of Chagas disease remains to be investigated.

\section{Abbreviations}

CD: Chagas disease; CCC: Chagas disease cardiomyopathy; IFN- - : Interferon gamma; TNF: Tumor necrosis factor; IL-6: Interleukin 6; IL-1 $\beta$ : Interleukin 1 beta; IL-4: Interleukin 4; IL-10: Interleukin 10; IL-12: Interleukin 12; CXCR3: C-XC motif chemokine receptor 3; CCR5: C-C chemokine receptor type 5; CXCL9: C-X-C motif chemokine ligand-9; CCL5: C-C motif chemokine ligand 5; CXCL10: C-X-C motif chemokine ligand-10; ECG: Electrocardiogram; MC: Minnesota code; LVH: Left ventricular hypertrophy; CBA: Cytometric bead array assay; CXCL8: C-X-C motif ligand 8; CCL2: C-C motif chemokine ligand 2; MoAb: Monoclonal antibody; BMI: Body mass index; BP: Blood pressure; NI: Seronegative non-infected; CH (N) ECG: Infected without major ECG abnormalities; CH (Ab) ECG: Infected with major ECG abnormality; BNP: Brain natriuretic peptide; MMP-9: Metalloproteinase 9; CD4+ T cells: CD4 T lymphocytes; CD8+ T cells: CD8 T lymphocytes

\section{Acknowledgments}

The authors thank the Program for Technological Development in Tools for Health-RPT-FIOCRUZ for the use of the flow cytometry facility. MFLC, SVP, ALPR, ATC and OAMF received financial support from CNPq PQ Fellowship Program and FFA received financial support from CNPq PDS Fellowship Program.

\section{Rights and permissions}

Open Access This article is distributed under the terms of the Creative Commons Attribution 4.0 International License (http://creativecommons.org/ licenses/by/4.0/), which permits unrestricted use, distribution, and reproduction in any medium, provided you give appropriate credit to the original author(s) and the source, provide a link to the Creative Commons license, and indicate if changes were made. The Creative Commons Public Domain Dedication waiver (http://creativecommons.org/publicdomain/ zero/1.0/) applies to the data made available in this article, unless otherwise stated.

\section{Authors' contributions}

OAMF, MFLC, FFA, KCLT, ATC, SVP and ALPR participated in the design of the study, drafting or revising the manuscript. FFA, KCLT, VBR, SVP and MLLS participated in obtaining the samples and conducting the experiments. FFA, KCLT, SVO, JVMN, AlLF participated in the statistical analysis. All authors read and approved the final manuscript.

\section{Authors' information}

Not applicable.

\section{Funding}

This work was supported by Fundação de Amparo à Pesquisa do Estado de Minas Gerais (FAPEMIG), PP-SUS CDS - APQ-03590-13 grant and by the Ministry of Health (DECIT), Ministry of Science and Technology (Conselho Nacional de Desenvolvimento Científico e Tecnológico - CNPq and FINEP) and Coordenação de Aperfeiçoamento de Pessoal de Nível Superior (CAPES).

\section{Availability of data and materials}

The datasets used and/or analyzed during the current study are available from the corresponding author on reasonable request.

\section{Ethics approval and consent to participate}

The Bambuí Cohort Study of Aging was approved by the Ethics Research Committee at Fundação Oswaldo Cruz (CAAE 01082212.7.0000.5091). All participants signed an informed consent for all procedures.

\section{Consent for publication}

All presentations of the data have consent for publication.

\section{Competing interests}

The authors declare that they have no competing interests.

\section{Author details}

${ }^{1}$ Integrated Research Group in Biomarkers, Rene Rachou Institute, Oswaldo Cruz Foundation, Avenida Augusto de Lima, 1715 - Barro Preto -, Belo Horizonte, Minas Gerais 30190-002, Brazil. José do Rosário Vellano University, UNIFENAS/BH, Belo Horizonte, Brazil. ${ }^{3}$ Center for Studies in Public Health and Aging, Rene Rachou Institute, Oswaldo Cruz Foundation, Belo Horizonte, Brazil. ${ }^{4}$ Clinical Hospital and Faculty of Medicine, Federal University of Minas Gerais, Belo Horizonte, Brazil.

Received: 8 January 2020 Accepted: 17 April 2020

Published online: 11 May 2020

\section{References}

1. Nunes MCP, Beaton A, Acquatella H, Bern C, Bolger AF, Echeverría LE, et al. Chagas cardiomyopathy: an update of current clinical knowledge and management: a scientific statement from the American Heart Association. Circulation. 2018. https://doi.org/10.1161/CIR.0000000000000599.

2. Coura JR. The main sceneries of Chagas disease transmission. The vectors, blood and oral transmissions - a comprehensive review. Mem. Inst. Oswaldo Cruz. 2015;110:277-82.

3. World Health Organization. Chagas Disease (American Trypanosomiasis). 2019 https://www.who.int/chagas/epidemiology/en/. Accessed 12 Dec 2019.

4. Benziger CP, do GAL C, ALP R. Chagas Cardiomyopathy: Clinical Presentation and Management in the Americas. Cardiol Clin. 2017. https:// doi.org/10.1016/j.ccl.2016.08.013.

5. Sabino EC, Ribeiro AL, Salemi VM, Di Lorenzo OC, Antunes AP, Menezes MM, et al. Ten-year incidence of Chagas cardiomyopathy among asymptomatic Trypanosoma cruzi-seropositive former blood donors. Circulation. 2013. https://doi.org/10.1161/circulationaha.112.123612.

6. Dutra WO, Gollob KJ, Pinto-Dias JC, Gazzinelli G, Correa-Oliveira R, Coffman $\mathrm{RL}$, et al. Cytokine mRNA profile of peripheral blood mononuclear cells isolated from individuals with Trypanosoma cruzi chronic infection. Scand J Immunol. 1997. https://doi.org/10.1046/j.1365-3083.1997.d01-362.x. 
7. Gomes JA, Bahia-Oliveira LM, Rocha MO, Martins-Filho OA, Gazzinelli G, Correa-Oliveira R. Evidence that development of severe cardiomyopathy in human Chagas disease is due to a Th1-specific immune response. Infect Immun. 2003. https://doi.org/10.1128/iai.71.3.1185-1193.2003.

8. Gomes JA, Bahia-Oliveira LM, Rocha MO, Busek SC, Teixeira MM, Silva JS, et al. Type 1 chemokine receptor expression in Chagas disease correlates with morbidity in cardiac patients. Infect Immun. 2005. https://doi.org/10. 1128/IAl.73.12.7960-7966.2005.

9. Souza PE, Rocha MO, Rocha-Vieira E, Menezes CA, Chaves AC, Gollob KJ, et al. Monocytes from patients with indeterminate and cardiac forms of Chagas disease display distinct phenotypic and functional characteristics associated with morbidity. Infect Immun. 2004. https://doi.org/10.1128/IAl. 72.9.5283-5291.2004.

10. Vitelli-Avelar DM, Sathler-Avelar R, Teixeira-Carvalho A, Pinto Dias JC, Gontijo ED, Faria AM, et al. Strategy to assess the overall cytokine profile of circulating leukocytes and its association with distinct clinical forms of human Chagas disease. Scand J Immunol. 2008. https://doi.org/10.1111/j. 1365-3083.2008.02167.x.

11. Bellini MF, Silistino-Souza R, Varella-Garcia M, de Azeredo-Oliveira MT, Silva AE. Biologic and genetics aspects of Chagas disease at endemic areas. J Trop Med. 2012. https://doi.org/10.1155/2012/357948.

12. Reis DD, Jones EM, Tostes S Jr, Lopes ER, Gazzinelli G, Colley DG, et al. Characterization of inflammatory infiltrates in chronic chagasic myocardial lesions: presence of tumor necrosis factor-a+ cells and dominance of granzyme $\mathrm{a}^{+}, \mathrm{CD}^{+}$lymphocytes. Am J Trop Med Hyg. 1993. https://doi.org/ 10.4269/ajtmh.1993.48.637.

13. Reis MM, Higuchi Mde L, Benvenuti LA, Aiello VD, Gutierrez PS, Bellotti G, et al. An in situ quantitative immunohistochemical study of cytokines and $\mathrm{IL}^{2}-\mathrm{R}^{+}$in chronic human chagasic myocarditis: correlation with the presence of myocardial Trypanosoma cruzi antigens. Clin Immunol Immunopathol. 1997. https://doi.org/10.1006/din.1997.4335.

14. Abel LC, Rizzo LV, lanni B, Albuquerque F, Bacal F, Carrara D, et al. Chronic Chagas disease cardiomyopathy patients display an increased IFN-gamma response to Trypanosoma cruzi infection. J Autoimmun. 2001. https://doi. org/10.1006/jaut.2001.0523.

15. Marino AP, da Silva A, dos Santos P, Pinto LM, Gazzinelli RT, Teixeira MM, et al. Regulated on activation, normal T cell expressed and secreted (RANTES) antagonist (met-RANTES) controls the early phase of Trypanosoma cruzi-elicited myocarditis. Circulation. 2004. https://doi.org/10.1161/01.CIR. 0000141561.15939.EC.

16. Machado FS, Koyama NS, Carregaro V, Ferreira BR, Milanezi CM, Teixeira MM, et al. CCR5 plays a critical role in the development of myocarditis and host protection in mice infected with Trypanosoma cruzi. J Infect Dis. 2005. https://doi.org/10.1086/427515.

17. Roffê E, Souza ALS, Caetano BC, Machado PP, Barcelos LS, Russo RC, et al. A DNA vaccine encoding CCL4/MIP-1 beta enhances myocarditis in experimental Trypanosoma cruzi infection in rats. Microbes Infect. 2006. https:/doi.org/10.1016/j. micinf.2006.08.004.

18. Cunha-Neto E, Nogueira LG, Teixeira PC, Ramasawmy R, Drigo SA, Goldberg AC, et al. Immunological and non-immunological effects of cytokines and chemokines in the pathogenesis of chronic Chagas disease cardiomyopathy. Mem Inst Oswaldo Cruz. 2009. https://doi.org/10.1590/s0074-02762009000900032.

19. Lima-Costa MF, Barreto SM, Guerra HL, Firmo JOA, Uchoa E, Vidigal PG. Ageing with Trypanosoma cruzi infection in a community where the transmission has been interrupted: the Bambui health and ageing study (BHAS). Int J Epidemiol. 2001. https://doi.org/10.1093/ije/30.4.887.

20. Lima-Costa MF, Peixoto SV, Ribeiro AL. Chagas disease and mortality in old age as an emerging issue: 10 year follow-up of the Bambui populationbased cohort study (Brazil). Int J Cardiol. 2010a. https://doi.org/10.1016/j. ijcard.2010.02.036

21. Lima-Costa MF, Matos DL, Ribeiro AL. Chagas disease predicts 10-year stroke mortality in community-dwelling elderly: the Bambui cohort study of aging. Stroke. 2010b. https://doi.org/10.1161/STROKEAHA.110.588061

22. Lima-Costa MF, Firmo JO, Uchoa E. Cohort profile: the Bambui (Brazil) cohort study of ageing. Int J Epidemiol. 2011. https://doi.org/10.1093/ije/ dyq143.

23. Dias JC, Matos CS. Seventy years of the Chagas disease Bambuí project: celebration and perspectives. Rev Soc Bras Med Trop. 2013. https://doi.org/ 10.1590/0037-8682-0175-2013.

24. Prineas RJ, Crow RS, Blackburn H. The Minnesota code manual of electrocardiographic findings. Littleton: John Wright-PSG; 1982.
25. Prineas RJ, Crow RS, Zhang ZM. The Minnesota code manual of electrocardiographic findings. 2nd ed. London: Springer; 2010.

26. Ribeiro AL, Marcolino MS, Prineas RJ, Lima-Costa MF. Electrocardiographic abnormalities in elderly Chagas disease patients: 10-year follow-up of the Bambui cohort study of aging. J Am Heart Assoc. 2014. https://doi.org/10. 1161/JAHA.113.000632.

27. Ramalho JR, Mambrini JV, César CC, de Oliveira CM, Firmo JO, Lima-Costa MF, et al. Physical activity and all-cause mortality among older Brazilian adults: 11-year follow-up of the Bambuí health and aging study. Clin Interv Aging. 2015. https://doi.org/10.2147/CIA.S74569.

28. Plan and operation of the Third National Health and Nutrition Examination Survey, 1988-94. Series 1: programs and collection procedures. Vital Health Stat 1. 1994;32:1-407.

29. Costa E, Barreto SM, Uchoa E, Firmo JO, Lima-Costa MF, Prince M. Is the GDS-30 better than the GHQ-12 for screening depression in elderly people in the community? The Bambui health aging study (BHAS). Int Psychogeriatr. 2006. https://doi.org/10.1017/S1041610205002954.

30. Blum A, Sclarovsky S, Rehavia E, Shohat B. Levels of T-lymphocyte subpopulations, interleukin-1 beta, and soluble interleukin-2 receptor in acute myocardial infarction. Am Heart J. 1994. https://doi.org/10.1016/00028703(94)90040-x.

31. Guillén I, Blanes M, Gómez-Lechón MJ, Castell JV. Cytokine signaling during myocardial infarction: sequential appearance of IL-1 beta and IL-6. Am J Physiol. 1995. https://doi.org/10.1152/ajpregu.1995.269.2.R229.

32. Ono K, Matsumori A, Shioi T, Furukawa Y, Sasayama S. Cytokine gene expression after myocardial infarction in rat hearts: possible implication in left ventricular remodeling. Circulation. 1998. https://doi.org/10.1161/01.cir.98.2.149.

33. Harada E, Nakagawa O, Yoshimura M, Harada M, Nakagawa M, Mizuno Y, et al. Effect of interleukin-1 beta on cardiac hypertrophy and production of natriuretic peptides in rat cardiocyte culture. J Mol Cell Cardiol. 1999. https://doi.org/10.1006/jmcc.1999.1030.

34. Sousa GR, Gomes JA, Fares RC, Damásio MP, Chaves AT, Ferreira KS, et al. Plasma cytokine expression is associated with cardiac morbidity in chagas disease. PLoS One. 2014. https://doi.org/10.1371/journal.pone.0087082.

35. Petersen CA, Burleigh BA. Role for interleukin-1 beta in Trypanosoma cruziinduced cardiomyocyte hypertrophy. Infect Immun. 2003. https://doi.org/10. 1128/iai.71.8.4441-4447.2003.

36. Machado FS, Tyler KM, Brant F, Esper L, Teixeira MM, Tanowitz HB. Pathogenesis of Chagas disease: time to move on. Front Biosci. 2012. https://doi.org/10.2741/495.

37. Medeiros $N I$, Pinto BF, Elói-Santos $S M$, Teixeira-Carvalho A, Magalhães LMD, Dutra WO, et al. Evidence of different IL-1 $\beta$ activation pathways in innate immune cells from indeterminate and cardiac patients with chronic Chagas disease. Front Immunol. 2019. https://doi.org/10.3389/fimmu.2019.00800.

38. Talvani A, Ribeiro CS, Aliberti JC, Michailowsky V, Santos PV, Murta SM, et al. Kinetics of cytokine gene expression in experimental chagasic cardiomyopathy: tissue parasitism and endogenous IFN- $y$ as important determinants of chemokine mRNA expression during infection with Trypanosoma cruzi. Microb Infect. 2000. https:/doi. org/10.1016/s1286-4579(00)00388-9.

39. Teixeira MM, Gazzinelli RT, Silva JS. Chemokines, inflammation and Trypanosoma cruzi infection. Trends Parasitol. 2002. https://doi.org/10.1016/ s1471-4922(02)02283-3.

40. dos Santos PVA, Roffê E, Santiago HC, Torres RA, Marino AP, Paiva CN, et al. Prevalence of $\mathrm{CD}^{+} \mathrm{T}$ cells in Trypanosoma cruzi-elicited myocarditis is associated with acquisition of CD62L Low LFA-1 ${ }^{\text {High }}$ VLA-4 ${ }^{\text {High }}$ activation phenotype and expression of IFN-y-inducible adhesion and chemoattractant molecules. Microbes Infect. 2001. https://doi.org/10.1016/ s1286-4579(01)01461-7.

41. Roffe E, Dos Santos LI, Santos MO, Henriques PM, Teixeira-Carvalho A, Martins-Filho OA, et al. Increased frequencies of circulating CCR5 ${ }^{+}$memory T cells are correlated to chronic chagasic cardiomyopathy progression. J Leukoc Biol. 2019. https://doi.org/10.1002/JLB.MA1118-472R.

42. Luz PR, Velavan TP, Kremsner PG, Messias-Reason IJT. Association of IP-10 and PDGF-BB levels with clinical forms of chronic Chagas disease. Int J Cardiol. 2013. https://doi.org/10.1016/j.jijcard.2013.08.110.

43. Crema E, Monteiro Ide O, Gomes MG, Silva AA, Rodriques JV. Evaluation of cytokines (MIG, IFN-gamma, TNF-alpha, IL-4, IL-5, and IL-10) during the different evolutive phases of chagasic esophagopathy. Clin Immunol. 2006. https://doi.org/10.1016/j.clim.2005.12.011.

44. Altara R, Mallat Z, Booz GW, Zouein FA. The CXCL10/CXCR3 Axis and cardiac inflammation: implications for immunotherapy to treat infectious and 
noninfectious diseases of the heart. J Immunol Res. 2016. https://doi.org/10. 1155/2016/4396368

45. Liu M, Guo S, Hibbert JM, Jain V, Singh N, Wilson NO, et al. CXCL10/IP-10 in infectious diseases pathogenesis and potential therapeutic implications. Cytokine Growth Factor Rev. 2011. https://doi.org/10.1016/j.cytogfr.2011.06.001. 46. Nogueira $L G$, Santos RHB, lanni BM, Fiorelli Al, Mairena EC, Benvenuti LA, et al. Myocardial chemokine expression and intensity of myocarditis in Chagas cardiomyopathy are controlled by polymorphisms in CXCL9 and CXCL10. PLoS Negl Trop Dis. 2012. https://doi.org/10.1371/journal.pntd.0001867.

Ready to submit your research? Choose BMC and benefit from:

- fast, convenient online submission

- thorough peer review by experienced researchers in your field

- rapid publication on acceptance

- support for research data, including large and complex data types

- gold Open Access which fosters wider collaboration and increased citations

- maximum visibility for your research: over $100 \mathrm{M}$ website views per year

At $\mathrm{BMC}$, research is always in progress.

Learn more biomedcentral.com/submissions 